\title{
ELECTROCHEMICAL REDUCTION OF SUBSTITUTED $\alpha, \alpha, \alpha$-TRIFLUOROACETOPHENONES. LINEAR RELATIONSHIP BETWEEN CYCLIC VOLTAMMETRIC PEAK POTENTIALS AND HAMMETT SUBSTITUENT CONSTANTS
}

\author{
JYE-SHANE YANG, KWANG-TING LIU* AND Y. OLIVER SU \\ Department of Chemistry, National Taiwan University, Taipei 10764, Taiwan, Republic of China
}

\begin{abstract}
The peak potentials of substituted $\alpha, \alpha, \alpha$-trifluoroacetophenones were measured in acetonitrile with $0.1 \mathrm{M}$ tetrabutylammonium perchlorate. The cyclic voltammograms indicated an irreversible electrochemical process for the first wave $\left(E_{\mathrm{pc} 1}\right)$ and a partially reversible one for the second wave $\left(E_{\mathrm{pc} 2}\right)$ when the scan rate was slower than $100 \mathrm{mV} \mathrm{s}^{-1}$. Excellent linear correlations were observed for $E_{\mathrm{pct}}$ with $\sigma$ constants $(\rho=0 \cdot 526, r=0.999)$ and for $E_{\mathrm{pc} 2}$ with $\sigma^{-}$constants $(\rho=0.605, r=0.998)$, respectively. Therefore, unknown $\sigma$ values such as -0.36 for 3,4-ethyleneoxy can be estimated from these correlations. The mechanism of the electrode process probably involves a single electron transfer and the formation of a pinacol.
\end{abstract}

\section{INTRODUCTION}

Correlation of polarographic half-wave potentials $\left(E_{1 / 2}\right)$ of organic compounds with a variety of parameters, e.g. ionization potentials $\left(I_{\mathrm{p}}\right),{ }^{1}$ electron affinities (EA) ${ }^{2}$ and Hammett substituent constants, ${ }^{3}$ has long been an important subject in physical organic chemistry. Both theoretical considerations ${ }^{4}$ and empirical data ${ }^{1-4}$ result in linear free energy relationships. $^{3}$ Recently we observed ${ }^{5}$ an excellent correlation of ${ }^{17} \mathrm{O}$ NMR chemical shifts with $\sigma^{+}$ substituent constants for substituted $\alpha, \alpha, \alpha$-trifluoroacetophenones. The results raised the question of whether there is also a linear correlation between the half-wave potentials for these ketones and the Hammett-type substituent constants.

The half-wave potential $\left(E_{1 / 2}\right)$ is usually obtained from polarographic measurement. From a cyclic voltammogram, $E_{1 / 2}$ can also be estimated in a reversible system by finding the mid-point of the cathodic peak potential $\left(E_{\mathrm{pc}}\right)$ and anodic peak potential $\left(E_{\mathrm{pa}}\right)$. In an irreversible system, $E_{1 / 2}$ cannot be obtained in the same way, because only $E_{\mathrm{pc}}$ or $E_{\mathrm{pa}}$ can be observed from the voltammogram. However, the difference in the peak potentials $\left(\Delta E_{\mathrm{p}}\right)$ would be same as that in the half-wave potentials $\left(\Delta E_{1 / 2}\right)$ for a series of compounds having the

${ }^{*}$ Author for correspondence.

0894-3230/90/110723-09\$05.00

(C) 1990 by John Wiley \& Sons, Ltd. same type of reducible centre under similar experimental conditions. This can be easily derived from the combination of equations $(1)^{6,7}$ and $(2)^{8}$ for a totally irreversible system in cyclic voltammetry $(\mathrm{CV})$ and in polarography, respectively, to give equation (3), where the symbols in these equations have usual meaning. ${ }^{6-8}$ That is, the $\Delta E_{\mathrm{p}}$ or $\Delta E_{1 / 2}$ will be directly related to the rate constant of heterogeneous electron transfer $\left(k_{\mathrm{f}}^{0}\right)$ at an electrode potential of $0 \mathrm{~V}$ as well as the free energy of activation for heterogeneous electron transfer (for the correlations using $E_{\mathrm{p} / 2}$ and $E_{\mathrm{p}}$ see, e.g., Refs 9 and 10 , respectively), since the other parameters $\left(v, \alpha n_{\mathrm{a}}, D_{0}, t_{1}\right.$ and $\left.T\right)$ are assumed to be constant, as are $R$ and $F$.

$$
\begin{aligned}
E_{\mathrm{p}} & =\frac{R T}{\alpha n_{\mathrm{a}} F}\left[-0 \cdot 780+\ln k_{\mathrm{f}}^{0}-\frac{1}{2} \ln \left(\frac{\alpha n_{\mathrm{a}} F D v}{R T}\right)\right] \\
E_{1 / 2} & =\frac{R T}{\alpha n_{\mathrm{a}} F} \ln 0 \cdot 87 k_{\mathrm{f}}^{0} \sqrt{t_{1} / D} \\
\Delta E_{\mathrm{p}} & =\Delta E_{1 / 2}=\frac{R T}{\alpha n_{\mathrm{a}} F} \Delta \ln k_{\mathrm{f}}^{0} \propto \Delta \Delta G^{\ddagger}(E)
\end{aligned}
$$

The first CV study on $\alpha, \alpha, \alpha$-trifluoroacetophenone in acetonitrile was reported by Andrieux and Saveant. ${ }^{11}$ The results of the photochemical reaction involving charge-transfer (CT) quenching of several substituted $\alpha, \alpha, \alpha$-trifluoroacetophenones were reported later ${ }^{12}$ and the half-wave potentials of these ketones measured at a 
hanging mercury drop electrode by $\mathrm{CV}$ in acetonitrile, were also listed, but no further discussion about the correlation with the structures of the ketones was given.

Therefore, we undertook to examine the relationship between the reduction potentials of a number of substituted $\alpha, \alpha, \alpha$-trifluoroacetophenones and the Hammett substituent constants in a CV study. In addition, the mechanism of the electrode process was also examined.

\section{RESULTS AND DISCUSSION}

\section{Cyclic voltammetry of $\alpha, \alpha, \alpha$-trifluoroacetophenones}

A typical cyclic voltammogram for $2 \mathrm{~mm}$ substituted $\alpha, \alpha, \alpha$-trifluoroacetophenones in acetonitrile solution with $0.1 \mathrm{M}$ tetrabutylammonium perchlorate (TBAP) as the supporting electrolyte is shown in Figure 1. The voltammograms of these ketones exhibit three distinct successive waves $\left(E_{\mathrm{pc} 1}, E_{\mathrm{pc} 2}\right.$ and $\left.E_{\mathrm{pc} 3}\right)$ in the potential range of -0.9 to $-2.5 \mathrm{~V}$. The reversibility of the first and second waves depends on the substituent. However, the third waves are usually too small and too broad to determine their peak potentials and reversibility.

On increasing the scan rate, the reversibility increases for the first waves, but decreases for the second. It is likely that some coupled irreversible chemical reactions occur after the first electron transfer, and the rate constants (forward and backward) of the second electron transfer are finite. Therefore, at high scan rates the backward process of the first electrode reaction will compete with the following chemical reaction, whereas the second electrode reaction will no longer be able to maintain equilibrium conditions as the potential
changes. ${ }^{7,13}$

The single-sweep CV data for substituted $\alpha, \alpha, \alpha$ trifluoroacetophenones and the corresponding substituent constants are given in Table 1. Owing to the strong electron-withdrawing ability of $\mathrm{CF}_{3}$, the electrode processes are accelerated and a lower reduction potential for $\alpha, \alpha, \alpha$-trifluoroacetophenone $\left(E_{1 / 2}=-1.42 \mathrm{~V}\right.$ vs SCE) than acetophenone $\left(E_{1 / 2}=-2 \cdot 06 \mathrm{~V} \text { vs SCE }\right)^{17}$ has been observed.

In this series of substituted $\alpha, \alpha, \alpha$-trifluoroacetophenones, the near constancy of the current function $i_{\mathrm{p}} / c v^{1 / 2}$ in Table 1 indicate ${ }^{10}$ that the diffusion coefficients are rather insensitive to structure. The values of the diffusion coefficients $(D)$, measured by chronoamperometry, for certain ketones (Table 2) also show agreement.

\section{Correlation of cathodic peak potentials with Hammett substituent constants}

The reversibility of electrode processes in $\mathrm{CV}$ for these ketones not only changes with the scan rate, but also is different from one to another at different scan rates. Nevertheless, when the scan rate is slower than $100 \mathrm{mV} \mathrm{s}^{-1}$, the first waves $\left(E_{\mathrm{pc} 1}\right)$ in all of the cyclic voltammograms of these ketones change gradually from partial reversibility to total irreversibility (Figure 2). This irreversibility suggests that the rate process of the subsequent chemical reaction is much faster than the reverse electron transfer, so the rate of the forward electron transfer becomes rate limiting, ${ }^{7,13}$ and that the properties of the electrode process are now

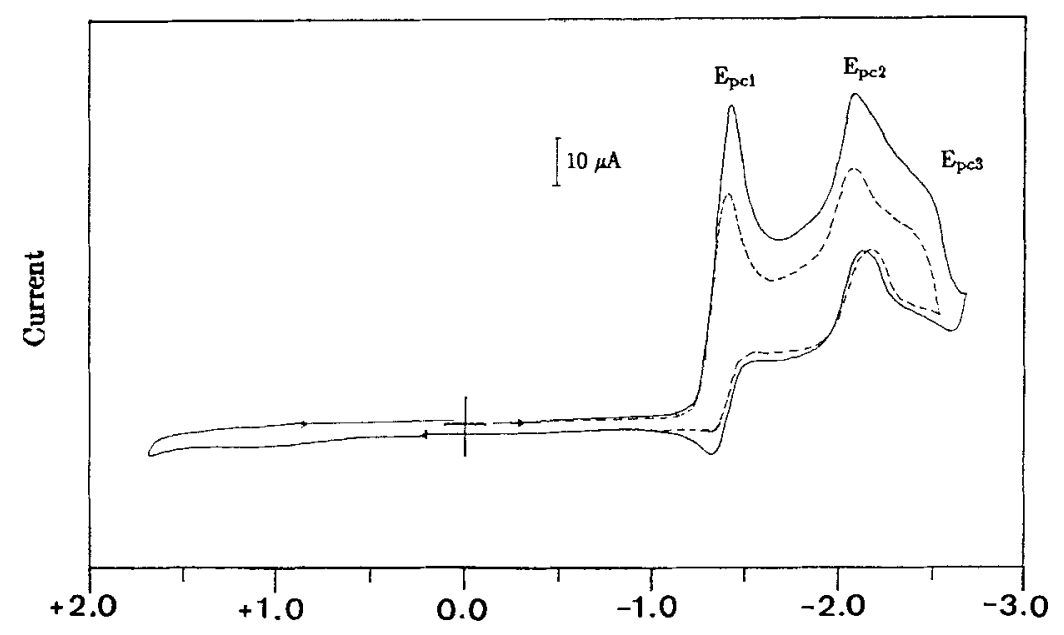

$\mathrm{E}, \mathrm{V}$ vs. $\mathrm{Ag} / \mathrm{AgCl}$

Figure 1. Cyclic voltammogram of $2 \mathrm{mM} \alpha, \alpha, \alpha$-trifluoroacetophenone in acetonitrile with $0.1 \mathrm{M}$ TBAP at a scan rate of $100 \mathrm{mV} \mathrm{s}^{-1}$ (full line) and $50 \mathrm{mV} \mathrm{s}^{-1}$ (dashed line) 
Table 1. Cyclic voltammetric data ${ }^{a}$ and Hammett substituent constants for

\begin{tabular}{|c|c|c|c|c|c|}
\hline $\mathrm{X}$ & $\sigma^{\mathrm{b}}$ & $\sigma^{-}$ & $E_{\mathrm{pcl} 1}^{c}(\mathrm{~V})$ & $E_{\mathrm{pc} 2}{ }^{\mathrm{d}}(\mathrm{V})$ & $i_{\mathrm{p}} / c v^{1 / 2 \mathrm{e}}$ \\
\hline $3-\mathrm{CH}_{2} \mathrm{CH}_{2} \mathrm{O}-4$ & $-0 \cdot 36^{f}$ & - & $\begin{array}{l}-1.593 \\
-1.635^{\mathrm{k}}\end{array}$ & $-2 \cdot 275$ & 0.0031 \\
\hline$p-\mathrm{OCH}_{3}$ & $-0 \cdot 268$ & $-0 \cdot 20^{b}$ & $\begin{array}{l}-1.546 \\
-1.582^{k}\end{array}$ & $-2 \cdot 216$ & $0 \cdot 0028$ \\
\hline$p-\mathrm{CH}_{3}$ & $-0 \cdot 17$ & $-0 \cdot 14^{8}$ & $\begin{array}{l}-1 \cdot 490 \\
-1 \cdot 505^{k}\end{array}$ & $-2 \cdot 168$ & $0 \cdot 0028$ \\
\hline $3-\mathrm{OCH}_{2} \mathrm{O}-4$ & $-0 \cdot 16^{\mathrm{h}}$ & - & $\begin{array}{l}-1 \cdot 483 \\
-1 \cdot 490^{\mathrm{k}}\end{array}$ & $-2 \cdot 138$ & 0.0031 \\
\hline$m-\mathrm{CH}_{3}$ & -0.069 & $-0.069^{i}$ & $\begin{array}{l}-1 \cdot 445 \\
-1 \cdot 463^{k}\end{array}$ & $-2 \cdot 137$ & $0 \cdot 0023$ \\
\hline$p$-OPh & $-0.055^{j}$ & $0.005^{\mathrm{g}}$ & $\begin{array}{l}-1 \cdot 431 \\
-1 \cdot 444^{\mathrm{k}}\end{array}$ & $-2 \cdot 073$ & 0.0026 \\
\hline $\mathrm{H}$ & 0 & 0 & $\begin{array}{l}-1 \cdot 398 \\
-1 \cdot 436^{k}\end{array}$ & $-2 \cdot 073$ & 0.0028 \\
\hline$m-\mathrm{F}$ & $0 \cdot 34$ & $0 \cdot 34^{i}$ & $\begin{array}{l}-1 \cdot 234 \\
-1 \cdot 260^{k}\end{array}$ & $-1 \cdot 890$ & 0.0026 \\
\hline$m-\mathrm{Cl}$ & $0 \cdot 37$ & $0.37^{i}$ & $\begin{array}{l}-1 \cdot 219 \\
-1 \cdot 237^{k}\end{array}$ & $-1 \cdot 853$ & $0 \cdot 0029$ \\
\hline$m-\mathrm{CF}_{3}$ & 0.43 & $0.43^{i}$ & $\begin{array}{l}-1 \cdot 169 \\
-1 \cdot 189^{k}\end{array}$ & $-1 \cdot 819$ & 0.0031 \\
\hline$p-C F_{3}$ & $0 \cdot 54$ & $0.62^{\mathrm{x}}$ & $\begin{array}{l}-1 \cdot 111 \\
-1 \cdot 122^{k}\end{array}$ & $-1 \cdot 725$ & 0.0031 \\
\hline$m m^{\prime}-\left(\mathrm{CF}_{3}\right)_{2}$ & $0 \cdot 82^{f}$ & - & $\begin{array}{l}-0.972 \\
-0.992^{k}\end{array}$ & $-1 \cdot 612$ & 0.0025 \\
\hline
\end{tabular}

${ }^{\text {a }}$ Measured with a glassy carbon electrode at a scan of $50 \mathrm{mV} \mathrm{s}^{-1}$ in acetonitrile with $0.1 \mathrm{M}$ TBAP at $22^{\circ} \mathrm{C}$ unless stated otherwise.

${ }^{b}$ Ref. 14.

${ }^{c}$ Reproducible within $\pm 0.005 \mathrm{~V}$.

${ }^{\mathrm{d}}$ Reproducible within $\pm 0.010 \mathrm{~V}$.

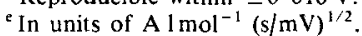

${ }^{\mathrm{f}}$ Extrapolated from $E_{\mathrm{pcl}}$ vs $\sigma$ plot (Figure 3).

${ }^{g}$ Ref. 15 .

${ }^{\text {hi }}$ Ref, 3 .

'Value as $\sigma$ used.

${ }^{i}$ Ref. 16.

${ }^{k}$ Potential was measured at a scan rate of $100 \mathrm{mV} \mathrm{s}^{-1}$.

just like those of a totally irreversible system. Hence a linear relationship between $E_{\mathrm{pc} 1}$ and $\sigma$ in terms of equation (3) would be expected. Indeed, an excellent linear relationship $(\rho=0.526, r=0.999$, s.d. $=0.008)$ in correlating $E_{\mathrm{pcl}}$ with $\sigma$ at $v=50 \mathrm{mVs}^{-1}$ is realized (Figure 3). At $v=100 \mathrm{mV} \mathrm{s}^{-1}$, the linear $E_{\mathrm{pc1}}$ vs $\sigma$ plot $(\rho=0.532, \quad r=0.996, \quad$ s.d. $=0.016)$ supports our assumption that the first electrode process in CV could be treated as an irreversible process for these ketones at scan rates slower than $100 \mathrm{mV} \mathrm{s}^{-1}$. Worse correlations with $\sigma^{018}(\rho=0.561, r=0.981$, s.d. $=0.039)$ and with $\sigma^{-14-16}(\rho=0.535, r=0.991$, s.d. $=0.027)$ have been observed at $v=50 \mathrm{mVs}^{-1}$.

Some quantitative criteria ${ }^{7,10}$ for total irreversibility in cyclic voltammetry have been developed which also support our assumption. One of the principal tests for electrochemical reversibility rests on the constancy of the transfer coefficient from various properties of the CV wave. The transfer coefficients calculated from equations (4),,$^{7,10}(5)^{7}$ and $(6)^{7,10}$ are listed in Table 3. The internal consistency in these values confirms that the first wave exhibits total irreversibility at scan rates slower than $100 \mathrm{mVs}^{-1}$.

$$
\begin{aligned}
E_{\mathrm{p}} & =\frac{2 \cdot 3 R T}{2 \alpha n_{\mathrm{a}} F} \log v+\text { constant } \\
E_{\mathrm{p}}-E_{\mathrm{p} / 2} & =1 \cdot 857\left(R T / \alpha n_{\mathrm{a}} F\right) \\
E_{\mathrm{p}} & =\frac{2 \cdot 3 R T}{2 \alpha n_{\mathrm{a}} F} \log i_{\mathrm{p}}+\text { constant }
\end{aligned}
$$


Table 2. Diffusion coefficients $(D)^{\mathrm{a}}$ and coulometric $n$ values ${ }^{\mathrm{b}}$ for selected ketones

\begin{tabular}{lccc}
\hline Substituent & $\begin{array}{c}10^{5} D \\
\left(\mathrm{~cm}^{2} \mathrm{~s}^{-1}\right)\end{array}$ & $n_{1}(E)$ & $n_{2}(E)$ \\
\hline $\mathrm{H}$ & $2 \cdot 9$ & $1.09(-1.70)$ & - \\
$p-\mathrm{CH}_{3}$ & 2.8 & $1.11(-1.70)$ & - \\
$m-\mathrm{CH}_{3}$ & 2.6 & $1.05(-1.65)$ & -- \\
$p-\mathrm{CF}_{3}$ & 2.9 & - & $2.12(-1.85)$ \\
$p-\mathrm{OPh}$ & 2.8 & $1.04(-1.40)$ & - \\
$m-\mathrm{F}$ & 2.9 & $1.04(-1.40)$ & $2.21(-2.00)$ \\
\hline
\end{tabular}

"Measured by chronoamperometry.

${ }^{\mathrm{h}}$ Measured by chronocoulometry.

The magnitude of the slope of the plot of $E_{\mathrm{p}}$ or $E_{\mathrm{p} / 2}$ vs $\log v$ is another probe for this purpose. ${ }^{10}$ Figure 2 shows the negative shift of peak potential when the scan rate changed from 10 to $100 \mathrm{mV} \mathrm{s}^{-1}$. The values (42-48) of slopes $(m)$ for these ketones shown in Table 3 are consistent with $30 / \alpha \mathrm{mV}$ negative shift per decade for a one-electron-transfer irreversible wave. ${ }^{7}$

The positive value of 0.526 for the reaction constant $\rho$ indicates a nucleophilic reaction ${ }^{19}$ and the aromatic ring has a higher electron density in the transition state than in the starting material. The electron on the electrode is probably the nucleophilic agent.

The $\sigma$ value of the 3,4-ethyleneoxy group could be estimated from coumaranyl trifluoromethyl ketone as -0.36 by extrapolation on the basis of the excellent linear $E_{\mathrm{pc} 1}$ vs $\sigma$ plot (open circle in Fig. 3). In addition, the $\sigma$ value of 0.82 for the $m, m^{\prime}$-bis(trifluoromethyl) group obtained by this method seems to be more appropriate than that usually suggested as double that of $\sigma_{m}\left(\mathrm{CF}_{3}\right), 0 \cdot 86$.

Although the different reversibility in $E_{\mathrm{p}<2}$ suggested that the correlation with $\sigma$ might not be good, the $E_{\mathrm{pc} 2}$ vs $\sigma$ plot showed the contrary $[\rho=0.582, r=0.994$,
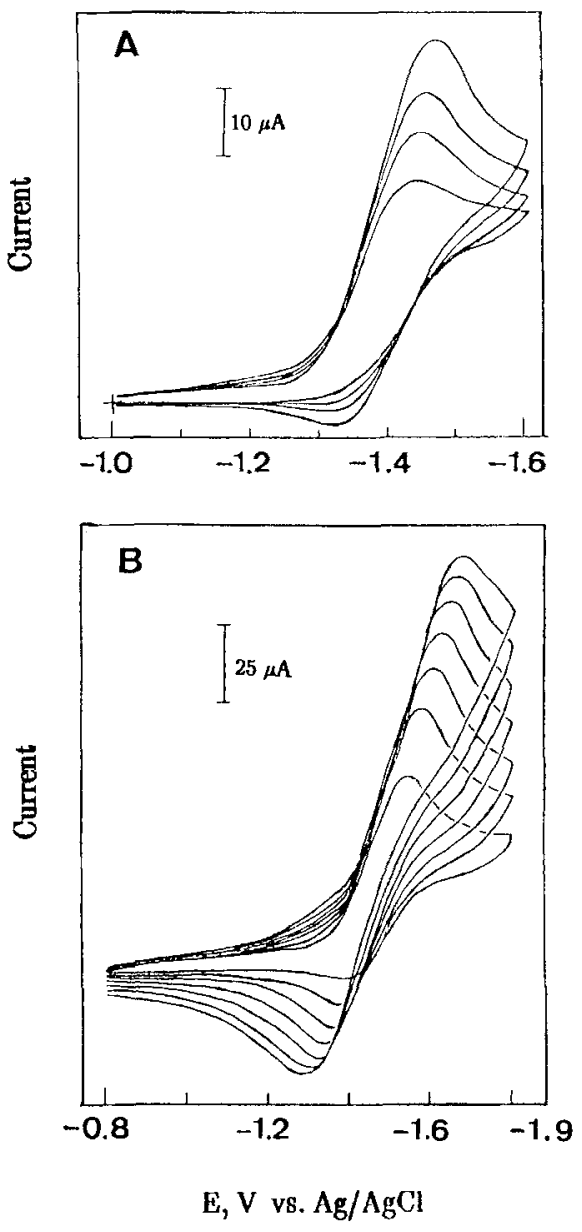

Figure 2. Dependence of peak potential of the first wave $\left(E_{\mathrm{pc} 1}\right)$ of 3-methyl- $\alpha, \alpha, \alpha$-trifluoroacetophenone on scan rate:

(A) $30<v<100 \mathrm{mVs}^{-1}$ and (B) $100<v<700 \mathrm{mV} \mathrm{s}^{-1}$

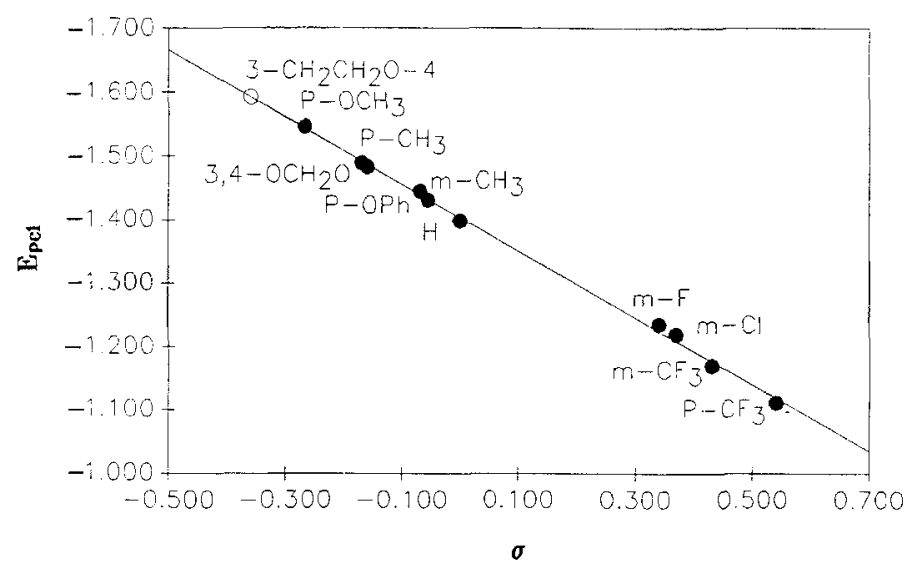

Figure 3. $E_{\mathrm{pc} 1}$ vs $\sigma$ plot for substituted $\alpha, \alpha, \alpha$-trifluoroacetophenones 
Table 3. Transfer coefficients determined by independent methods $^{\mathrm{a}}$

\begin{tabular}{lccccc}
\hline & \multicolumn{5}{c}{ Transfer coefficient } \\
\cline { 3 - 6 } Substituent & $m^{\mathbf{b}}$ & $E_{\mathbf{p}}$ vs $\log v$ & $E_{\mathrm{p}}-E_{\mathbf{p} / 2}$ & $E_{\mathrm{p}}$ vs $\log { }_{i \mathrm{p}}$ & $\mathrm{Av} .^{\mathrm{c}}$ \\
\hline $\mathrm{H}$ & 45 & 0.65 & 0.66 & 0.57 & 0.63 \\
$p-\mathrm{OCH}_{3}$ & 45 & 0.65 & 0.62 & 0.54 & 0.60 \\
$m-\mathrm{CH}_{3}$ & 47 & 0.62 & 0.62 & 0.57 & 0.60 \\
$m-\mathrm{Cl}$ & 42 & 0.70 & 0.65 & 0.70 & 0.68 \\
$m-\mathrm{F}$ & 48 & 0.61 & 0.65 & 0.55 & 0.60 \\
$m-\mathrm{CF}_{3}$ & 46 & 0.64 & 0.65 & 0.58 & 0.62 \\
\hline
\end{tabular}

${ }^{\mathrm{a}} E_{\mathrm{p}}$ refers to $E_{\mathrm{pc} 1}$.

"The slope of $E_{\mathrm{pc} 1}$ vs $\log v$ for $v<100 \mathrm{mV} \mathrm{s}^{-1}$

${ }^{c}$ Average: \pm 0.05 .

s.d. $=0.023$, Figure 4(A)]. If the second peak potentials were plotted against $\sigma^{-}$instead $\sigma$, an even better correlation $[\rho=0.605, r=0.998$, s.d. $=0.015$ ), Figure 4(B)] resulted.
Mechanism of the cyclic voltammetric electrode process

A number of possible processes for the electroreduction of carbonyl compounds have been summarized, ${ }^{20}$ and a series of papers and a broad survey of the literature on early work on the reduction of aromatic carbonyl compounds are available. ${ }^{21}$ The reduction of $\alpha, \alpha, \alpha$ trifluoroacetophenone has also been studied. ${ }^{11,22}$ Based on our findings, the overall mechanism of the $\mathrm{CV}$ of $\alpha, \alpha, \alpha$-trifluoroacetophenones in acetonitrile with $0.1 \mathrm{M}$ TBAP as supporting electrolyte could be as illustrated in Scheme 1.

From theoretical considerations, the $m$ values (the slope of the $E_{\mathrm{p}}$ vs $\log v$ plot) for $\alpha, \alpha, \alpha$-trifluoroacetophenones (Table 3 ) fit the diagnostic criteria of a so-called 'ePrrcp' mechanism. ${ }^{23}$ According to this reaction pathway, the rate-determining step is the forward reaction of the preceding proton transfer equilibrium (step 2) after a rapid reversible electron transfer (step 1) and than a fast radical--radical coupling ( $\mathrm{rrc}$ ) reaction (step 3 ). That is, once the neutral
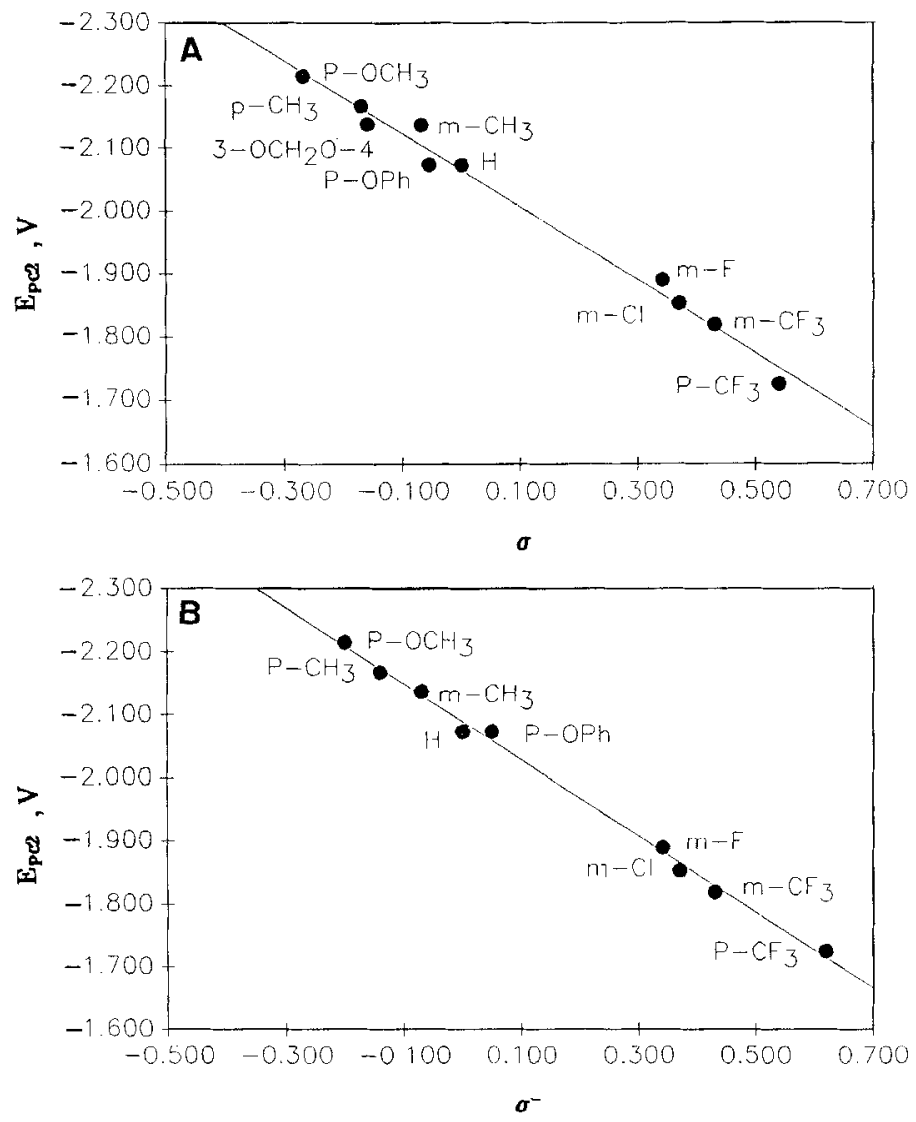

Figure 4. (A) $E_{\mathrm{pc} 2}$ vs $\sigma$ plot and (B) $E_{\mathrm{pc} 2}$ vs $\sigma^{-}$plot for substituted $\alpha, \alpha, \alpha$-trifluoroacetophenones 

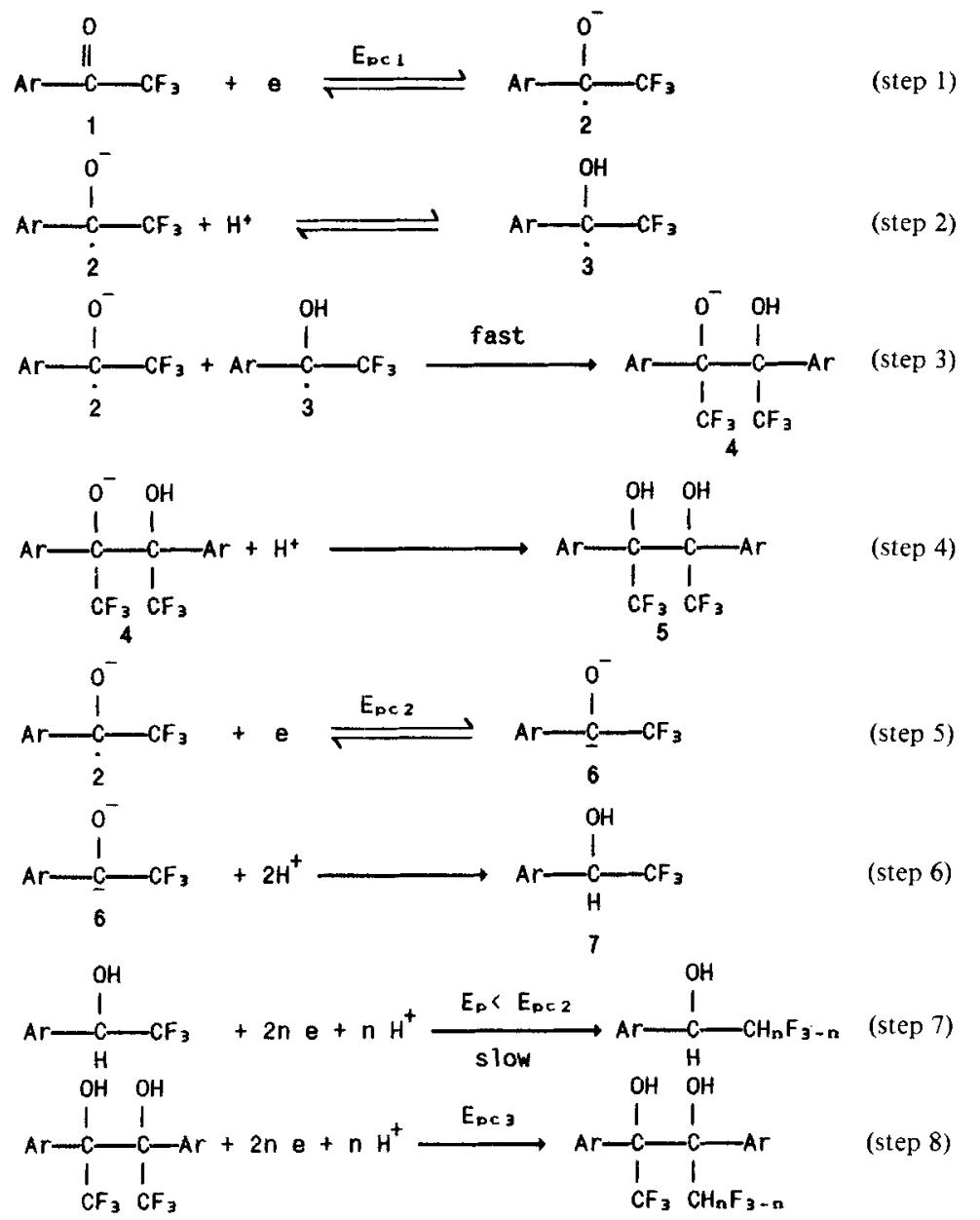

Scheme 1. Mechanism of electrode reactions and chemical reactions in CV of substituted $\alpha, \alpha, \alpha$-trifluoroacetophenones

radical 3 forms in the neighbourhood of the electrode, it couples with the newly formed radical anion 2 to give a pinacol 5 after the protonation step (step 4). The irreversibility of the first waves could be due to the competition of a moderately fast and irreversible rrc reaction. The proton source may be the trace amount of water present in the solvent ${ }^{24}$ When the concentration of proton increases in the solution, the preceding proton transfer would be more favourable and then a more irreversible wave would be observed (see below). The $n$ values for some ketones, listed in Table 2, also indicated that the first wave, in addition to the second wave, was a one-electron transfer process (steps 1 and 5). Moreover, the observed linear correlation with $\sigma^{-}$ for $E_{\mathrm{pc} 2}$ suggests that the aromatic ring would have a partial negative charge in the transition state in the second electrode process (step 5), and eventually the dianion would be protonated ${ }^{21,24}$ to give the alcohol 7 (step 6).

The third wave (Figure 1) could be due to the reduction of the $\mathrm{C}-\mathrm{F}$ bond in the $\alpha, \alpha, \alpha$-trifluoromethyl group. The electrolytic reduction of the $\mathrm{C}-\mathrm{F}$ bond in $\alpha, \alpha, \alpha$-trifluoroacetophenone had even been noted in protic solvent. ${ }^{22}$ Figure 5 shows the cyclic voltammograms of $\alpha, \alpha, \alpha$-trifluoroacetophenone, 1,1,1,4,4,4-hexafluoro-2,3-diphenylbutane-2,3-diol and 1-phenyl-2,2,2-trifluoroethanol. The last two compounds did undergo electrode reactions, which should come from the reduction of the $\mathrm{C}-\mathrm{F}$ bond in the $\mathrm{CF}_{3}$ group, whereas the broad and low current peaks might be due to the slow rate of electron transfer and the complicated electrode processes, producing different F-containing alcohols or pinacols (steps 7 and 8). On the other hand, from a comparison of their 




Figure 5. Cyclic voltammograms of (A) $\alpha, \alpha, \alpha-$ trifluoroacetophenone, (B) 1,1,1,4,4,4-hexafluoro-2,3diphenylbutane-2,3-diol (pinacol 5 in Scheme 1) and (C) 1-phenyl-2,2,2-trifluoroethanol (alcohol 7 in Scheme 1) in acetonitrile with $0.1 \mathrm{M}$ TBAP (full line) and with $2 \%$ water added (dashed line) at a scan rate of $100 \mathrm{mV} \mathrm{s}^{-1}$ relative peak potentials, it seems that the third wave just represents the reduction of pinacols formed after the first reduction in the carbonyl group of ketones (step 8), whereas the reduction of alcohols is probably immersed in the second wave (step 7).

Wawzonek and Gundersen ${ }^{25}$ suggested that the positive shift of peak potentials on the addition of water could be used to detect the different influences of radical anion 2 and dianion 6 in studying the polarography of acetophenone. Andrieux and Saveant also studied 11 the effect of the addition of water in linear voltammetry. Figure 6 shows the positive shift of peak potential for the $m$-CF $\mathrm{CF}_{3}$-substituted ketone on addition of $2 \%$ of water. The larger shift of the second wave $\left(E_{\mathrm{pc} 2} \rightarrow E_{\mathrm{pc} 2}^{\prime}\right)(180 \mathrm{mV})$ than the first $\left(E_{\mathrm{pcl}} \rightarrow E_{\mathrm{pc1}}^{\prime}\right)$ $(100 \mathrm{mV})$ indicates that the second wave should be the reduction of the radical anion 2 (step 5), and not the neutral radical $3 .^{21,25,26}$ It is worth noting that a new peak is present, designated $E_{\mathrm{pw}}$, between $E_{\mathrm{pcl}}^{\prime}$ and $E_{\mathrm{pc} 2}^{\prime}$ in Figure 6, in addition to Figure 5(A). This phenomenon was observed for all the ketones, but the degree of decay of $E_{\mathrm{pc} 1}$ or the growth of $E_{\mathrm{pw}}$ were different. It is known ${ }^{11,27}$ that these ketones are apt to undergo hydration to form gem-diols:<smiles>O=C([Al])[14CH2][Te]C(O)(O)C(F)(F)F</smiles>

Thus the stronger the electron-withdrawing substituent, the easier was gem-diol formation and then the more decay in $E_{\mathrm{pcl}}$ was observed, as predicted. This electrode

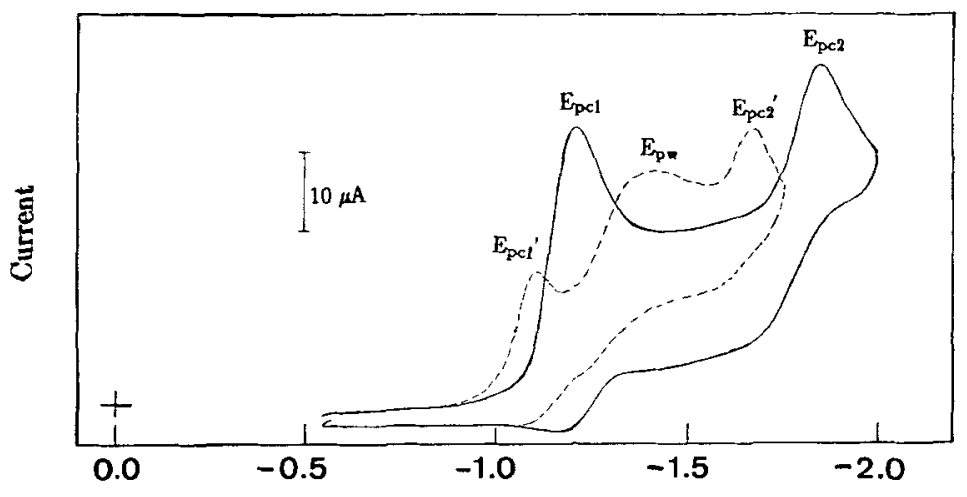

$\mathrm{E}, \mathrm{V}$ vs. $\mathrm{Ag} / \mathrm{AgCl}$

Figure 6. Cyclic voltammograms of 3-methyl- $\alpha, \alpha, \alpha$-trifluoroacetophenone in acetonitrile with $0 \cdot 1 \mathrm{M}$ TBAP (full line) and $2 \%$ water added (dashed line) at a scan rate of $100 \mathrm{mV} \mathrm{s}^{-1}$ 


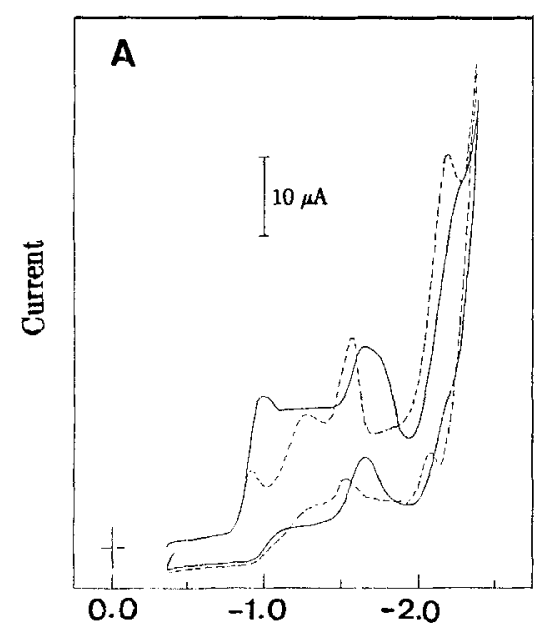

E, $V$ vs. $\mathrm{Ag} / \mathrm{AgCl}$

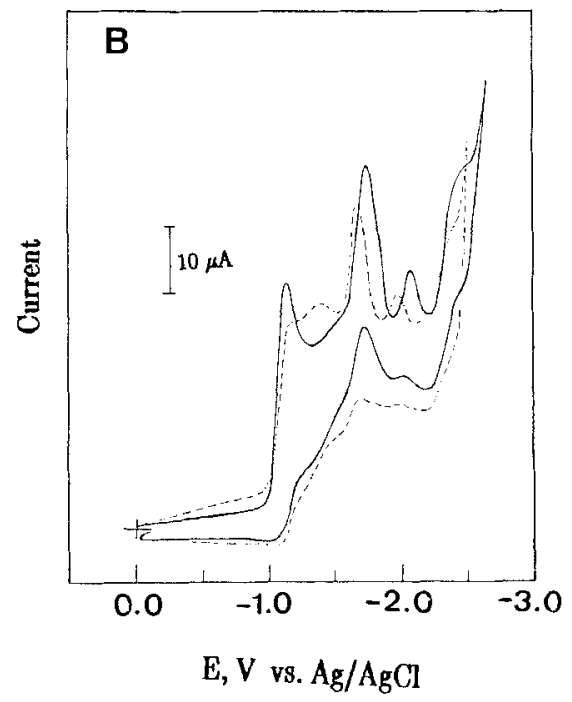

Figure 7. Cyclic voltammograms of (A) 3,5-bistrifluoromethly- $\alpha, \alpha, \alpha$-trifluoroacetophenone and (B) 4-trifluoromethyl- $\alpha, \alpha, \alpha$ trifluoroacetophenone in acetonitrile and $0.1 \mathrm{M}$ TBAP (full line) and $2 \%$ water added (dashed line)

reaction may be the reduction of the neutral radical 3:

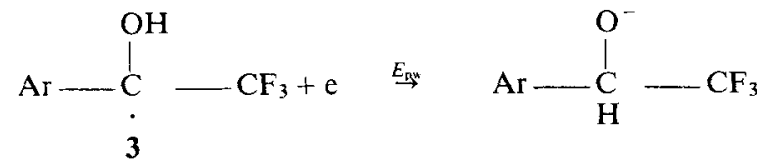

since the dimerization process shifts the first wave $\left(E_{\mathrm{pc}}\right)$ towards more anodic potentials and then two separated waves ( $E_{\mathrm{pc} 1}^{\prime}$ and $E_{\mathrm{pw}}$ ) can be observed even if the standard potential of the latter is more positive than that of the former. ${ }^{21}$ The reason why this electrode reaction was insignificant in anhydrous acetonitrile could be attributed to the low concentration of proton source in the solution. When water is added, the third wave in Figure 5(A) is influenced even more than the second, which indicates that the fission of the $\mathrm{C}-\mathrm{F}$ bond becomes easier in the presence of water. ${ }^{28}$

Moreover, the $\mathrm{CV}$ behaviours of the $p-\mathrm{CF}_{3}$ - and $m, m^{\prime}-\left(\mathrm{CF}_{3}\right)_{2}$-substituted ketones shown in Figure 7 are different from the others, with more waves at the more cathodic potential, and this might have resulted from the reduction of $\mathrm{CF}_{3}$ in aryl groups (for previous instances of the electrochemical reduction of trifluoromethyl compounds see Refs 29 and 30). However, this reduction would be more difficult ${ }^{30}$ in the $m-C_{3}$-substituted ketone and therefore similar reduction peak(s) was not observed in the potential window.

It has been established ${ }^{11}$ that pinacol is produced in the presence of lithium cation in the large-scale electrolysis of $\alpha, \alpha, \alpha$-trifluoroacetophenone. In order to examine the pinacol formation in the solution system without $\mathrm{Li}^{+}$, large-scale electrolysis of $\alpha, \alpha, \alpha^{-}$ trifluoroacetophenone at $E_{\mathrm{pc}}$ was carried out and the product analysis showed about a $10 \%$ yield of a pinacol, $\mathrm{CF}_{3} \mathrm{CPh}(\mathrm{OH}) \mathrm{CPh}(\mathrm{OH}) \mathrm{CF}_{3}$, detected by gas chromatography, together with a large amount of intractable tars. On controlling the potential at $E_{\mathrm{pc} 2}$, the same pinacol was also obtained ( $\mathrm{Ca} 4 \%$ ), which suggested further electron transfer in the radical anions 2 . No defluorinated product ${ }^{22}$ was detected, probably owing to the different reaction conditions employed.

\section{EXPERIMENTAL}

Materials. Acetonitrile (Hayashi), employed as a solvent, was purified ${ }^{3 !}$ by heating under reflux with calcium hydride for at least $8 \mathrm{~h}$ under nitrogen, followed by distillation prior to use. The potential window with $0.1 \mathrm{M}$ TBAP was found to be from +1.7 to $-2 \cdot 7 \mathrm{~V}$ vs a $\mathrm{Ag} / \mathrm{AgCl}(\mathrm{KCl}$ saturated) reference electrode.

Tetrabutylammonium perchlorate (TBAP) (Tokyo Kasei), the supporting electrolyte, was recrystallized from absolute ethanol followed by drying in vacuo at room temperature for $24 \mathrm{~h}$.

Commercial $\alpha, \alpha, \alpha$-Trifluoroacetophenone (Merck) was used without further purification. All of the substituted ketones were prepared from the reaction of the appropriate arylmagnesium bromide in diethyl ether with 1.2 equiv. of trifluoroacetic anhydride under reflux. The ketones were isolated by vacuum distillation $(30-60 \%)$ and then further purified by column chromatography on silica gel. 5.32

1,1,1,4,4,4,-Hexafluoro-2,3-diphenylbutane-2,3-diol, m.p. $152-153^{\circ} \mathrm{C}$ (uncorrected; lit., ${ }^{33,34} 155-156^{\circ} \mathrm{C}$ ) and 1-phenyl-2,2,2-trifluoroethanol, the GC standards, were prepared from $\alpha, \alpha, \alpha$-trifluoroacetophenone by 
photochemical irradiation ${ }^{34}$ and by sodium tetrahydroborate reaction, respectively.

Electrochemical instruments. A glassy carbon electrode (BAS GCE-63 grade carbon) was used for CV experiments with an area of $7.05 \times 10^{-2} \mathrm{~cm}^{2}$, measured from the analysis of the chronoamperometric $i-t$ transient of $4 \mathrm{mM}$ hexacyanoferrate(III) in $1.0 \mathrm{M} \mathrm{KCl}$ solution, ${ }^{31}$ in which the diffusion coefficient is $D=0.763 \times 10^{-5} \mathrm{~cm}^{2} \mathrm{~s}^{-1}$. In every experiment, the electrode was newly hand-polished with aluminium oxide (first $0.3 \mu \mathrm{m}$ and then $0.05 \mu \mathrm{m}$ ) and felt pads (Buehler) on a flat glass plate to a mirror-like finish, rinsed with distilled water, cleaned ultrasonically for 2 min, rinsed with distilled water and then dried at $100^{\circ} \mathrm{C}$.

Reticulated platinum electrodes were used as cathodes for chronocoulometry and large-scale controlled-potential electrolysis. A platinum wire was used as the auxiliary electrode and an $\mathrm{Ag} / \mathrm{AgCl}$ electrode as the reference electrode in all electrochemical experiments.

In performing $\mathrm{CV}$ experiments, a three-electrode, single-compartment cell was used. Prior to use, the reference electrode was calibrated with an aqueous saturated calomel electrode (SCE). The measurements were carried out with a BAS Model CV-27 394 potentiostat and a BAS Model C1B-120 267 cell stander. Cyclic voltammograms were obtained with a BAS Model RXY $226 X-Y$ recorder in a solution of $2 \mathrm{mM}$ ketones in acetonitrile containing $0.1 \mathrm{M}$ TBAP at room temperature $\left(\mathrm{ca} 22^{\circ} \mathrm{C}\right.$ ). All potentials were recorded with respect to the reference electrode.

The chronoamperometric $i-t$ curves and chronocoulometric curves were recorded with a BAS Model RYYT-DP 182 recorder with the same solution as in $\mathrm{CV}$.

For large-scale electrolyses $(3 \mathrm{mmol})$ at a reticulated carbon electrode, a two-compartment $\mathrm{H}$-cell was used. The same solvent and supporting electrolyte as in $\mathrm{CV}$ were used.

Product analysis. Gas chromatographic analysis was performed on a $10-\mathrm{m}$ Carbowax $20 \mathrm{M}$ column using a Hewlett-Packard Model 5890 instrument.

\section{ACKNOWLEDGEMENT}

The authors are indebted to the National Science Council for financial support of this research.

\section{REFERENCES}

1. M. Pomerantz, D. S. Marynick, K. Rajeshwar, W.-N. Chou, L. Throckmorton, E. W. Tsai, P. C. Y. Chen and T. Chain, J. Org. Chem. 51, 1223 (1986).

2. G. Paul and P. Kebarle, J. Am. Chem. Soc. 111, 464 (1989).
3. P. Zuman, Substituent Effects in Organic Polarography, Chapt. II, and references cited therein. Plenum Press, New York (1967).

4. P. Zuman, Collect. Czech. Chem. Commun. 25, 3225 (1960).

5. K.-T. Liu, T.-R. Wu and Y.-C. Lin, J. Phys. Org. Chem. 2, 363 (1989).

6. H. Matsuda and Y. Ayabe, Z. Electrochem, 59, 494 (1955).

7. R. S. Nicholson and I. Shain, Anal. Chem. 36, 706 (1964).

8. P. Delahay, J. Am. Chem. Soc. 76, 5417 (1954).

9. K. Mukai, Y. Kageyama, T. Ishida and K. Fukuda, $J$. Org. Chem. 54, 552 (1989).

10. R. J. Klingler and J. K. Kochi, J. Am. Chem. Soc. 102, $4790(1980)$, and references cited therein.

11. C. P. Andrieux and J. M. Saveant, Bull. Soc. Chim. Fr. 6, 2090 (1973).

12. P. J. Wagner and M. H. Lam, J. Am. Chem. Soc. 102, 4167 (1980).

13. R. J. Klingler and J. K. Kochi, J. Phys. Chem. 85, 1731 (1981).

14. C. D. Ritche and W. F. Sager, Prog. Phys. Org. Chem. 2, 323 (1964).

15. O. Exner, Correlation Analysis of Chemical Data. Plenum Press, New York, London (1988).

16. M. Sjostrom and S. Wold, Chem. Scr. 9, 100 (1976)

17. P. J. Wagner and R. A. Leavitt, J. Am. Chem. Soc. 95, 3669 (1973).

18. M. Fujio, M. Goto, A. Murata, Y. Tsuji, M. Mishima and Y. Tsuno, Mem. Fac. Sci. Kyushu Univ, 16, 271 (1988).

19. L. P. Hammett, Physical Organic Chemistry. McGrawHill, New York (1940).

20. M. M. Baizer and H. Lound, Organic Electrochemistry, Marcel Dekker, New York (1983).

21. L. Nadjo and J. M. Saveant, J. Electroanal. Chem. 33, 419 (1971).

22. J. H. Stocker and R. M. Jenevein, J. Chem. Soc., Chem. Commun. 934 (1968).

23. L. Nadjo and J. M. Saveant, J. Electroanal. Chem, 44, 327 (1973).

24. L. Nadjo and J. M. Saveant, J. Electroanal. Chem. 30, 41 (1971).

25. S. Wawazonek and A. Gundersen, J. Electrochem. Soc. 107, 537 (1960).

26. A. Inesi, L. Rampazzo and A. Zeppa, J. Electroanal. Chem. 122, 233 (1981).

27. R. Stewart and J. D. van Dyke, Can. J. Chem. 50, 1992 (1972).

28. P. J. Elving and J. T. Leone, J. Am. Chem. Soc. 79, 1546 (1957).

29. H. Lund and N. J. Jensen, Acta Chem. Scand. 28, 263 (1974); J. P. Coleman, Naser-ud-din, H. G. Gilde, J. H. P. Utley, B. C. L. Weedon and L. Eberson, J. Chem. Soc., Perkin Trans. 21903 (1973).

30. A. 1. Cohen, B. T. Kfeler, N. H. Coy and H. L. Yale, Anal. Chem. 34, 216 (1962).

31. R. N. Adams, Electrochemistry at Solid Electrodes. Marcel Dekker, New York (1969).

32. M. S. Newman and A. S. Smith, J. Org. Chem. 13, 592 (1948).

33. W. A. Mosher and N. D. Heindel, J, Am. Chem. Soc. 85, 1548 (1963).

34. W. S. Cripps and C. J. Ellis, Can. J. Chem. 53, 817 (1975). 